\title{
CARDIAC IRREGULARITIES DURING LABOUR IN PARAPLEGIC WOMEN
}

\author{
By Drs. H. L. Frankel, L. Guttmann and V. Paeslack \\ National Spinal Injuries Centre, Stoke Mandeville Hospital, Aylesbury, England \\ (Paper presented by Dr. Frankel)
}

PARAPLEGIC women with complete lesions of the spinal cord above the splanchnic outflow develop, during the final stages of labour, in particular just before and during labour, the classical symptoms of reflex hyperactivity of autonomic mechanisms (hyperextension, bradycardia, outbursts of vasodilatation of the face, headaches, and sweating), as described by Guttmann and Whitteridge, 1947, due to detrusor activity of the bladder. These symptoms are closely related to the uterine contractions and disappear or are greatly diminished during the free intervals. Moreover, they disappear completely after delivery of the placenta.

A case of a woman with a complete transverse lesion below $\mathrm{T}_{5}$ is described, who, during the uterine contractions in the later stages of labour and especially during delivery, developed profound disturbances of the cardiac rhythm which were studied in detail electromyographically. Deformities of $\mathrm{A}-\mathrm{V}$ conduction, varying from simple prolongation of the P-R interval to second degree block with $\mathrm{A}-\mathrm{V}$ nodal escape beats, disappearance of the $\mathrm{P}$-waves and, during the actual delivery of the child, ventricular extrasystoles occurred in different directions and were of different shape.

A full account of this case has been published in Vol. 3, No. 2, p. I44, of this journal.

\section{PREGNANCY AND LABOUR IN COMPLETE TETRAPLEGIA}

By A. G. Hardy, M.B.E., F.R.C.S., and D. W. Warrell, M.D., M.R.C.O.G. Spinal Injuries Unit, Lodge Moor Hospital, Sheffield, England

(Paper presented by Dr. Hardy)

THE occurrence of pregnancy in patients with paralytic disorders must give rise to anxiety on a number of counts. The increased incidence and greatly improved chances of survival in traumatic paraplegia in women have provided increased opportunities for observation on this comparatively uncommon combination of circumstances. Reports of 17 cases of pregnancy and labour in traumatic paraplegia were made by Guttmann (1963) and a further case was detailed by Jackson (1964). These reports clearly indicate that there are definite hazards to mother and unborn child. They also indicate that successful spontaneous delivery can occur after a full-term pregnancy in certain circumstances.

This paper reports a pregnancy and labour in a case of traumatic tetraplegia arising from a fracture dislocation of the 5 th and 6 th cervical vertebrae sustained as a result of a motor-car accident. 